\title{
Efeitos de humor no poema VIII de Catulo
}

\author{
PAULO SÉRGIO DE VASCONCELLOS \\ Departamento de Linguística \\ Instituto de Estudos da Linguagem \\ Universidade Estadual de Campinas
}

\begin{abstract}
RESLM0
$\mathrm{N}$ este artigo apresenta-se uma contribuição a estudo dos efeitos de humor no poema VIII de Catulo; de fato, além do metro dessa composição e de outros elementos criadores de distanciamento irônico que os estudiosos têm apontado, um outro aspecto de sua forma, ainda pouco percebido, guia a leitura para essa interpretação: o jogo, à maneira de anagrama imperfeito (o "hipograma", ou, mais precisamente, "criptograma", de Saussure), com os sons do nome da amada, aparentemente calado. É mais uma das maneiras com que o poeta elabora a jocosa diferença entre o que se diz e o que, sentido e reprimido, deixa-se, porém, transparecer.
\end{abstract}

Palavras-chave: Poesia latina; Catulo; Coliambo.

$\mathrm{N}$

inguém ousará hoje negar, assim o cremos, que, no tão discutido poema VIII de Catulo, há boa dose de humor; ficaríamos perplexos, talvez, se alguém manifestasse hoje, diante de sua leitura, os mesmos sentimentos que o historiador inglês Macaulay dizia sentir, incapaz de ler tais versos sem chorar... (Fordyce, 1961, p. 110), ${ }^{1}$ exemplo siginificativo de uma certa recepção romântica da poesia subjetiva latina. ${ }^{2}$ Nosso objetivo ao retornar a um

\footnotetext{
${ }^{1}$ Mas já em 1909, Morris (apud Wheeler, 1974, p. 228-229) apontava o lado humorístico do poema, em análise algo viciada, contudo, pelo biografismo. Por outro lado, ressalvemos que o universo (no sentido etimológico do termo) de leituras desse nosso poema é absolutamente insondável e imponderável, em face do que observamos na nota seguinte; entretanto, por vícios de escola..., o estudioso tende a chamar leitores, sem adjetivação, apenas a certo leitor "ideal", supostamente privilegiado e exclusivo, aquele esclarecido pela literatura filológica... uma ave raríssima ou quase extinta em um país como o nosso...

2 Certos teóricos da literatura argumentariam que mesmo nossa proposta de leitura não "romântica" é datada, inserida no tempo, como qualquer outra, e, portanto, discutível, além de pretensiosa; um texto latino, como qualquer outro texto literário (como todo texto?) não contém uma verdade atemporal que caberia ao estudioso-filólogo determinar, mas instaura, como qualquer outro, o espaço de signos para infinitas possíveis (re)leituras - não é possivel abordá-lo sem intermediação de nosso próprio universo cultural. Entretanto, parece-nos óbvio que há leituras mais opacas do que outras, que perdem mais elementos da significação e sectariamente deixam de lado o que não cabe em seu esquema interpretativo - riscos sobretudo das leituras sociologizantes, "feministas", "psicológicas", etc.; assim, uma leitura exclusivamente sentimental do
} 
texto tão comentado e debatido é fornecer uma breve leitura de alguns elementos cômicos desse poema, ainda não percebidos, ao que nos conta. Para chegarmos a essa meta, porém, será interessante recordar alguns indícios que apontam para uma leitura em que o jocoso, ainda que não exclua o sentimental e o patético (parece-nos que essa mescla de tons, tipicamente alexandrina e, portanto, neotérica, também aqui se faz presente), perpassa o conjunto do texto.

Inicialmente, é preciso falar do metro, o chamado "iambo manco" (coliambo), hiponacteu ou "escazão", um trímetro iâmbico com um troqueu ou espondeu no último pé. Como se sabe, essa ruptura brusca do ritmo cria um efeito de estranheza que era utilizado por seu provável criador, Hipônax de Éfeso, para criar ou realçar o cômico. Catulo o emprega em oito poemas, dentre os quais os de número $22,37,39,44$ e 59 são claramente satíricos, em maior ou menor grau; excluindo-se o 8, que aqui discutiremos, restam os de número 31 e 60.031 dirige uma saudação à Península de Sírmio, onde a família do poeta possuía uma casa, e o tom é festivo:

Salue, o uenusta Sirmio, atque ero gaude;

Gaudete uosque, o Lydiae lacus undae;

Ridete, quicquid est domi cacbinnorum. (v. 12-14)

"Salve, ó encantadora Sírmio, e com teu senhor alegra-te;

Alegrai-vos também, ó ondas lídias do lago;

Ride, gargalhadas, quantas em casa houver!"

Resta o de número 60, queixa contra alguém "de coração demasiado cruel", em cinco versos, com referências mitológicas, helenismo no léxico (leaena), adjetivo raro (libjstinis) e um tópos que remonta a Homero e Eurípides. Se tendemos a ver funcionalidade no emprego do coliambo, isto é, se achamos que tal verso era empregado em poesias com algum traço que fosse de ironia ou festividade, este poema apresenta-nos uma incógnita. Mas resta o fato de que em Catulo o metro é empregado prevalentemente em composições de certo tipo; somos levados a crer que uma certa jocosidade, comum em tantas nugae de Catulo, é a característica compartilhada por esse conjunto; quanto à exceção, talvez não seja despropositado recordar que o metro definidor da elegia, o dístico justamente chamado elegíaco, também se empregou, especialmente em suas origens gregas, com outros conteúdos que não os da elegia amorosa latina (pensemos em Sólon, por exemplo).

Concentremo-nos brevemente nessa relação entre métrica e tema: teria havido o sentimento, entre os poetas da Antigüidade e, por certo, seu público, de uma adequação entre, por

poema VIII não deixa espaço para o humor e a ironia, que cabe ao estudioso revelar, sem pretensões de ter descoberto $a$ chave interpretativa. Por outro lado, reconstituir dados da recepção do leitor implícito não é sém interesse, ainda que se defenda a parcialidade dessa tarefa: trata-se de respeitar a alteridade, a historicidade, a emergência de uma voz do passado que difere da nossa tradição cultural mais próxima. 
exemplo, o metro elegíaco e seus conteúdos mais freqüientes?

Pierre Grimal, em seu Le Lyrisme à Rome, dá uma explicação para o emprego do dís tico elegíaco na poesia de tom melancólico ou choroso: ao hexâmetro dactîlico regular se sucede um pentâmetro que constitui, de fato, duas tripodias dactílicas catalépticas justapostas, dando a impressão "d'un développement heurté, comme brisé par un sanglot" (p. 117). Horácio também aponta a associação original do metro ao tema; o dístico teria sido empregado num primeiro momento para a poesia do lamento:

\section{Versibus impariter iunctis querimonia primum (De Arte Poetica, v. 75)}

"Na união de versos desiguais (encerrou-se), primeiramente, o lamento..."

Notemos querimonia, na elegia I, 18, de Propércio, que traz a situação elegíaca típica: em metro elegíaco, num ambiente de bucólica, o primeiro verso programaticamente anuncia a mescla de gêneros, ou, se se prefere, a ambientação bucólica da situação elegíaca; a última palavra do primeiro hexâmetro como que anuncia a interferência genérica:

\section{Haec certe deserta loca et taciturna querenti}

"Estes lugares desertos e taciturnos são ideais para quem se lamenta..."

Um exemplo claríssimo de que o dístico elegíaco era sentido como apropriado ao amor infeliz, temos no mesmo Ovídio; numa epístola das Heróidas, Safo, prevendo o espanto de seu Fáon por receber dela versos elegíacos, justifica o abandono dos metros em que ela se especializara pela mudança de tema - deve cantar matéria adequada à elegia:

\section{Forsitan et quare mea sint alterna requiras \\ Carmina, cum lyricis sim magis apta modis. \\ Flendus amor meus est; elegia flebile carmen; \\ Non facit ad lacrimas barbitos ulla meas. (XV, v. 5-8) \\ "Talvez perguntes por que sejam alternados \\ Meus versos, embora seja melhor nos ritmos líricos. \\ Devo chorar meu amor; a elegia é poema choroso; \\ Não se ajusta a minhas lágrimas lira alguma".}

A ruptura da expectativa - a um ritmo dactilico regular segue-se um esquema que parece quebrar a estutura rítmica anterior - pode, talvez, explicar não só a adequação do dístico aos versos de tom tristonho como também, em sua evolução, aos epigramas satíricos (paradoxo saboroso) e à poesia de invectiva: o efeito de ruptura certamente era sentido como apto a reproduzir a expressão de afetos intensos ou de uma dissonância explorada para fins cômi$\cos$. Ao falar de sua renúncia a escrever uma epopéia para se dedicar aos seus Amores, Ovídio 
conta que começara a compor hexâmetros mas que veio Cupido e roubou um pé do segundo verso (unum surrupuisse pedem - I, 1, v. 4): o pentâmetro é, pois, visto como uma espécie de hexâmetro de ritmo quebrado, lacunar, que, num dístico, rompe com a sublimidade do primeiro verso (o próprio Horácio, no passo citado mais acima, compara o dístico a uma parelha de cavalos desiguais, "um mais fraco" atrelado a "outro mais forte", na interpretação de Rostagni), como a contraposição ovidiana parece nos mostrar bem:

Sex mibi sugart opus numeris, in quinque residat! (Amores, I, 1, v. 27)

"Que a obra se me alce em seis pés, em cinco se abaixe!"

Os verbos grifados são empregados de forma ambígua: que a obra se inicie com seis e termine com cinco pés, mas também se eleve com o hexâmetro e se abaixe, isto é, desça das alturas a que aparentemente se elevara, com o pentâmetro: ao primeiro pé adequado a matéria nobre e solene se sucede um pé diverso, que cria o efeito de distorção, um como que hexâmetro abortado...

Por outro lado, verificaremos facilmente que o dístico elegíaco, considerado por excelência o metro do lamento, não se restringe aos conteúdos elegíacos; assim, seria preciso distinguir a especialização de uma dada forma a uma certa temática, tal como a podemos sentir a partir da prática concreta dos poetas, e sua eventual utilização minoritária em outros domínios; a obsevação é sobretudo relevante para nos prevenir contra uma demasiado superficial consideração dos gêneros a partir dos metros, afinal, a partir da tradição, os poetas podem (e, de fato, comumente, fazem-no) jogar com as expectativas do leitor diante de um certo ritmo temos um exemplo instigante na décima bucólica, tal como revelado pela leitura de Gian Biagio Conte. (Conte, 1984, p. 13)

Se o dístico elegíaco parece apropriado aos lamentos, seu emprego não se limita à elegia amorosa; similarmente, se o hexâmetro, por exemplo, é metro épico por excelência, e os Antigos tentavam explicar por quê, ${ }^{3}$ é também empregado na poesia didática, nos idílios virgilianos e em certos epigramas de Marcial. Concluamos: também o coliambo, ritmo da jocosidade, não se reduz aos versos satíricos, apesar de ser sentido como especialmente apto a esse uso.

3 Para Aristóteles, o chamado verso "heróico" é adequado à epopéia porque "é o mais grave e o mais amplo" e por isso "acolhe melhor vocábulos raros e metafóricos" (Poética, XXIV, 154, trad. de Eudoro de Souza). Ovídio o chama de grauis e adequado a tratar das façanhas bélicas:

\section{Arma graui numero uiolentaque bella parabam}

Edere, materia conveniente modis. (Amores, I, 1, v. 1-2)

"Armas e violentas guerras, num ritmo grave, preparava-me

Para celebrar, matéria adequada a essa cadência".

Notemos a arma inicial, a evocar, sem sombra de dúvida, a mais célebre epopéia dos Romanos, a Eneida.

Expressando a desistência de compor uma epopéia, diz o poeta: 
No entanto, se a consideração do metro por si só pode não parecer decisiva, ${ }^{4}$ a presença de outros elementos que apontam para uma "intenção" (no sentido da intentio operis de Eco) humorística, leva-nos a ver nos coliambos do poema VIII de Catulo sua feição satírica mais comum. Pouparemos o leitor de uma leitura mais detalhada do poema, especialmente porque já o fizemos numa dissertação de mestrado; deter-nos-emos no que nos parece ser seu aspecto humorístico mais visível, para então acrescentarmos algo à leitura que a crítica vem realizando nesse campo dos efeitos do humor.

No poema VIII, o leitor como que surpreende um momento de monólogo interior em "Catulo", na verdade um diálogo, pois que nesse poeta o solilóquio é dramatizado na "conversa" de duas instâncias de sua persona; como no poema 76, "Catulo 1", através de pensamentos cheios de bom-senso romano, tenta levar "Catulo 2" a renunciar a uma paixão que só causa infelicidade; como se vê, trata-se de incursão catuliana pelo gênero da renuntiatio amoris (Cairns, 1972, p. 80). 5 "Encenação" semelhante de conflito interior se encontraria no poema 51, se a última estrofe dessa ode sáfica pertence mesmo a tal composição, do que estamos mais do que convencidos (dentre outros motivos, por razões formais: nesses últimos versos se repete a forte aliteração em $/ t /$ que permeia quase todo o restante do poema).

Depois de mencionar um passado de felicidade (destacado pela Ringkomposition), quando a puella e "Catulo" tinham a mesma vontade, ele se exorta à renúncia, a também "não querer", agora que a moça "já não quer" - total submissão do apaixonado ao arbítrio de um outro que Lucrécio denunciara como um dos malefícios da paixão (De Rerum Natura, IV, 1.115). ${ }^{6}$ Como alguém que aparenta ter aprendido bem a lição de moral de um tutor, "Catulo" se dirige à moça:

Ferrea cum uestris bella ualete modis! (v. 28)

"Férreas guerras, com vossa cadência, adeus!"

Também Horácio aponta a adequação do hexâmetro a esse tipo de temática:

Res gestae regumque ducumque et tristia bella

quo scribi possent mumero, monstrauit Homerus. (De Arte Poetica, v. 73-74)

"As façanhas dos reis e dos chefes e as tristes guerras, en que metro se poderiam narrá-las, mostrou Homero".

4 Mas leiam-se as considerações de Achcar, 1994, sobre o efeito humorístico da nota dissonante propiciada pelo metro neste poema (pp. 17-18).

5 Um belo exemplo de que os poetas usam com liberdade e criatividade os tópicos de determinado "gênero": aqui, trata-se de uma tentativa de renuntiatio, cujo fracasso o leitor acompanhará ao longo dos versos. No poema LXXVI, apela-se aos deuses para a solução de um conflito que parece humanamente insanável.

6 Note-se o expressivo quiasmo:

Quae $t u$ uolebas nec puella nolebat. (v. 7)

Nunc illa non uolt; $t u$ quoque, impotens, noli (v. 9)

0 jogo com os nomes e pronomes que representam amante e amada prossegue:

Vale, puella. Iam Catullus obdurat. (v. 12)

A alternância contínua entre um e outro ressalta a discordância, a cisão das vontades outrora irmanadas. Vê-se quão burilado ( igilatum) é este poema que aparenta a espontaneidade de uma conversa consigo mesmo em tom confessional. 
Vale puella. Iam Catullus obdurat, nec te requiret nec rogabit inuitam. (v. 9-10)

Inuitam: novamente, se a moça não quer, "Catulo" também não deve querer... Mas os versos que seguem acabam revelando que, apesar do tom aparentemente decidido, "Catulo" continua apaixonado, dependente e atado ao passado. Prevê um futuro triste para a amada: em interrogativas retóricas aparentes ("Quem se apaixonará de ti?", isto é, "Ninguém se aproximará de ti"), com o ritmo sôfrego das anáforas, parece acreditar que a garota não será por mais ninguém amada, ao passo que o tom deixa transparecer preocupação, sofrimento, tensão. Catulo ameaça a amada com a visão de um futuro a ela cruel, mas parece chegar à conclusão não explicitada de que seu próprio destino é que se afigura penoso. Aqui, o brilho técnico dessa composição: o poeta consegue criar "falas" de uma personagem cujo conteúdo superficial é desmentido pelo modo de enunciação, sem necessidade de apor comentário algum, adendo algum, a não ser o verso final de todo o poema: "At tu, Catulle, destinatus obdura". (v. 19)

"Catulo" se incitara à resolução decidida: obdura (v. 11); dirigira-se à sua garota dizendo-se já mudado: Iam Catullus obdurat (v. 12); no verso final, o imperativo volta - obdura, mostrando que a lição não foi aprendida, que Catulo sofre, ama, não esquece: em suma, não deixou de querer. Assim, o verso final irradia sobre o que precede a desconfiança de que " $\mathrm{Ca}$ tulo" expressa uma determinação que está muito longe dele. Mais intrigante: At tu, Catulle evoca 0 anterior $A t t u$ dolebis (v. 14), que saberemos dirigido à moça ao final do verso. Quando se lê At tu dolebis, num poema em que o eu-poético conversa consigo, de início se é confundido: esse $t u$ que sofrerá é Catulo; a sequiência do verso (cum rogaberis nulla, apontando para o sujeito feminino) nos diz que é a amada, ao passo que a sequiência do poema nos sugere que, de fato, é Catulo... Trata-se de um jogo sutil entre o que se diz e o que se deixa dizer nas entrelinhas. ${ }^{7}$

Algo, porém, deve ser notado: quem é a tal puella? Ninguém duvida de que é Lésbia, especialmente porque a puella de sua poesia erótica é Lésbia, num ciclo comparável ao dos poemas a Cíntia, a garota properciana. Mas o nome da amada é calado. Aparece como puella (v. 7 e 12), illa (v. 9), quae fugit (10) e tu (v. 14). É interessante que os prazeres do passado recordados com nostalgia são designados também por uma illa (iocosa), neutro plural; assim, o verso 9 admitiria outra interpretação que se somaria à que todo mundo, inclusisve nós, fazemos:

Nunc iam illa non uolt: tu quoque impotens noli

"Agora ela já não quer; tu também, fraco, não queiras..."

${ }^{7}$ Que o tema deveria ser tópico, comprova-0, além de Plauto (Truculentus, v. 759-769; Bacchides, v. 500-525 - exemplos apontados por Morris apud Wheeler, 1974, p. 229) e os elegíacos, uma sentença de Publilio Siro: amans iratus multa mentitur sibi: no poema de Catulo, o amante, etiquetado como Catullus, deixa transparecer ao leitor sua vã auto-ilusão... 
"Agora (ela) já não quer (aquelas coisas prazerosas que mencionei...); tu também não queiras..."

Mas o que realmente nos motivou a voltar a tratar deste poema vem dito a seguir. Charles Martin vê em dolebis o anagrama (é verdade que imperfeito) de...Lésbia (Martin, 1992, p. 110), uma leitura que queremos referendar e desenvolver. De fato, parece-nos significativo que "Catulo" cale o nome da amada e a ela só se refira indiretamente:" aparenta distanciamento; mas os sons de seu dolebis, anagrama "involuntário" perpetrado pela persona Catullus, revela, em novo jogo entre aparência e desmascaramento, que a paixão continua intensa e obsessiva... Para nós, o nome da amada é também sugerido por outros sons que percorrem os versos finais e que evocam Lésbia:

doLEBIS...nuLLA (v. 14)
uidEBERIS BELLA (v. 16)
laBELLA mordEBIS (v. 18).

Ao leitor do ciclo esses sons, reiterados, em anagramas imperfeitos ou criptogramas (reiteração sonora, em anagramas, de "nomes ou palavras que não são pronunciados no decorrer da peça", na definição de Saussure, 1978, p. 17), fazem ecoar o nome da amada: notemos, sobretudo, os dois jogos fônicos finais, criados a partir de expressões da linguagem coloquial (bella, labella), numa espécie de quiasmo, se podemos empregar esse termo fora do âmbito restrito da sintaxe.

Ao descobrir esses anagramas, somos tomados de um ceticismo inicial e receamos, ao propor tal análise, estar imbuídos daquele "descarado heroísmo de afirmar" que, para o Raposão de A Relíquia, "cria, através da universal ilusão, ciências e religiões"..., mas a reflexão sobre a estrutura do poema, com aquele desmascarar para o leitor da fala superficial do eupoético, a consideração de que o nome da amada é superficialmente silenciado, o jogo At tu, Catulle (tu = Catulo), At tu dolebis (tu = Lésbia), confirma-nos a possibilidade de aqui estar uma faceta mais sutil e particularmente saborosa de seu humor, que teria passado desper-

\footnotetext{
${ }^{8}$ No poema LXXVI, que condivide com o poema VIII em mais de uma caracterítica: o solilóquio dramatizado, em auto-incitação à renúncia (v. 10-12, 14-16), um possivel eco verbal (desinis esse miser, v. 12/Miser Catulle, desinas inpertire, VIII, 1), o tópos da renuntiatio amoris impossível, a sugestão de um investimento emocional que dá em nada (Omniaque * ingratae perierunt credita menti, v. 9/ Et quod uides perisse, perditum ducas, VIII, v. 2), nesta bela elegia, de notável pátbos, o nome da amada também não é expresso, ao passo que o de Catulo, sim (Catulle, v. 5) - ela é a ingratae ...menti (v. 9) e illa, um efeito de distanciamento que julgamos comparável ao do poema VII. Em leitura que leve em conta o ciclo de Lésbia, Illa evoca, ao lado das conexões intertextuais, essa amada cujo nome se silencia. Mas nem é preciso dizer que, ao contrário do que ocorre no poema VIII, não há sinal de jocosidade, o tom é elegíaco no sentido primeiro do termo, e a mudança de metro (o coliambo pelo dístico elegíaco) parece sinalizar para a diferença de tom: estamos longe do tom ligeiro e por vezes francamente humorístico de certa produção elegíaca da época de Augusto. É curioso que illa $(m)$ também designe a amada no poema XCII, após o nome Lésbia ter sido expresso duas vezes, em contraposição a ego (Lesbia mi.../ Lesbia me..., v. 1-2) e venha salientado, o lado do nome próprio, no poema LVII: Lesbia illa,/llla Lesbia, em quiasmo.
} 
cebida aos estudiosos da obra de Catulo.

Ao invés de falarmos em "anagramas" imperfeitos, poderíamos tomar ao mesmo Saussure sua definição de "hipogramas", um dos vários termos que o linguiista empregou, em curiosa vacilação quanto à terminologia, para destacar um fenômeno percebido especialmente no verso satúrnio latino:

(...) trata-se ainda no "bipograma" de sublinbar um nome, uma palavra, esforçando-se por repetir-lhe as silabas, e dando-lhe uma segunda maneira de ser, fictícia, acrescentada, por assim dizer, à forma original da palaura (p. 14).

Talvez menos evidentes, mas dignas de nota estas outras reiterações fônicas: ${ }^{9}$

Fulsere quondam candidi tibi soles. (cf.: dolebis)

Cum uentitabas quo puella ducebat

Amata nobis quantum amabitur nulla.

Ibi illa multa tum iocosa fiebant,

Quae tu nolebas nec puella nolebat.

Fulsere uere candidi tibi soles. (v. 3-8)

Notáveis as assonâncias em /a/, /e/ e /i/, as vogais do nome Lesbia.

Alguns números sobre a repetição de sons que recordariam, no conjunto, o nome silenciado mas presente pela evocação criptográfica:

$l e(s)$ - oito vezes (Catulle, duas vezes; soles, duas vezes; iolebas; nolebat; dolebis; scelesta); note-se que em três passos vemos surgir toda a silaba inicial les (v. 3, 8 e 15);

$b i$-doze vezes (tibi, três vezes; nobis; amabitur; i $b i$; rogabit; dole $b i s ;$ adi $b i t$; amabis; basia $b i$ s; mordebis;

$a$ - notável: a mata nobis quantum amabitur nulla (v. 5)

Ibi illa multa tum iocosa fiebant (v. 6) ${ }^{10}$

Pode-se ainda ressaltar a presença de outras associações (como os sons $b a$ e $b e$, reiterados cinco e duas vezes, respectivamente; a forte repetição dos $l l$, em dez palavras), mas pessoalmente preferimos focalizar a evocação do nome Lésbia nos versos finais do poema, a nosso ver uma evidência, cujo sentido já interpretamos.

Se nossa leitura é correta, o jogo fônico do poema VIII de Catulo é absolutamente semelhante ao identificado por Saussure em sua análise de versos latinos e gregos: reiteração,

\footnotetext{
9 Levou-me a essa análise uma observação sobre a forte presença dos / 1 /, feita por meu aluno José Carlos Bacarat Júnior, a quem aqui agradeço.

${ }^{10}$ A quantidade, como se vê, não prepondera sobre o timbre da vogal a ponto de excluir certos sons do anagramático; já o observara Saussure.
} 
pela evocação dos sons que o compõem, de uma "palavra-tema", geralmente um nome próprio, quase criptográfica, ainda que certamente mais evidente para os leitores da Antigüidade, superiormente sensiveis à parte material dos signos de uma literatura feita para ser lida em voz alta.

Uma associação que não encontramos em Saussure, mas que nos parece relevante: sabe-se que nos hinos religiosos e situações de discurso similares bem como na poesia amorosa dos latinos, pode-se identificar um outro tipo de reiteração fônica, de matiz originalmente religioso, comparável à do "hipograma", cuja origem, na expressão cautelosa de Saussure, pode ter sido também religiosa: ${ }^{11}$ como já apontamos em trabalhos anteriores, no chamado "Hino a Vênus" de Lucrécio, bem como no poema LI de Catulo ou em trecho do canto quarto da Eneida, reiteram-se obsessivamente os sons que evocam a segunda pessoa, $t u$, seja através da repetição do pronome em vários casos, seja através dos sons no interior de outras palavras, o que geralmente se associa com uma forte aliteração em / $t$. Ilustremos com versos de Lucrécio (assinalamos em negrito a reiteração direta ou indireta do pronome de segunda pessoa do singular em vários casos, e em itálico a aliteração em / $\mathrm{V}$ não assinalada nos pronomes):

per te quoniam genus omne animant $u \mathrm{~m}$

Concipitur, uisitque exortum lumina solis:

$T e$, dea, $t e$ fugiunt $t$ uenti, $t e$ nubila caeli,

Aduentumque $t u$ um; $t i b i$ suaues daedala tellus

Summit $t$ it flores; tibi rident aequora ponti,

Placatumque nitet diffuso lumine caelum. (I, v. 4-9)

Pois que é através de ti que toda espécie de seres animados

é concebida e contempla, ao nascer, a luz do sol:

de ti.fogem, ó deusa, de ti os ventos, de ti as nuvens do céu,

e de teu advento; para ti, suaves, a industriosa terra

produz flores; para ti sorriem os plainos do pélago

e serenado se inunda de luz o céu.

A evidente reiteração fônica dos sons evocativos da segunda pessoa mostra que o princípio da composição em anagramas na poesia dos Antigos, defendido por Saussure (para quem até na prosa os escritores pareciam obedecer ao exercício do criptograma da palavratema), ${ }^{12}$ não é, afinal de contas, fenômeno tão singular a nos fazer ceticamente pensar em excessos interpretativos; veja-se como o texto de Lucrécio (aceite-se ou não a análise do lin-

11 "A razão pode ter residido na idéia religiosa de que uma inovação, uma prece, um hino, só produzia efeito com a condição de misturar as silabas do nome divino ao texto". (1978, p. 22)

${ }^{12}$ Entre hesitações e cautelas, uma afirmação mais enfática (e, sem dúvida, equivocada em seu exagero): "Desde os mais antigos monumentos saturninos até a poesia latina que se fazia em 1815 ou 1820, não houve jamais outra maneira de escrever versos latinos senāo parafraseando cada nome pró-prio sob as formas reguladas do hipograma...". (Starobinski, 1974, p. 90) 
güista, que vê ao longo de toda a invocação o criptograma de Afrodite) insiste numa série de sons que parecem presentificar a força divina da deusa invocada na própria composição. Similarmente, no poema LI de Catulo o poder de Lésbia sobre Catullus é realçado pela ênfase na segunda pessoa e, no poema VIII, criptograficamente, na evocação do nome ausente da puella.

Por outro lado, esse aspecto verdadeiramente lúdico da poesia não era trascurado pelos alexandrinos, e não o seria pelos neotéricos. Ilustremos com acrósticos que a crítica recente descobriu em Aratos e Virgílio. 0 primeiro, num passo dos Fenômenos, traz:

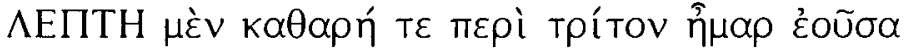

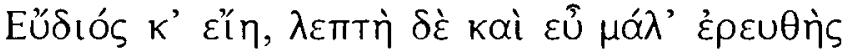

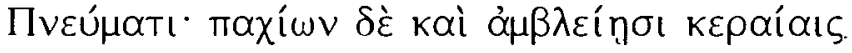

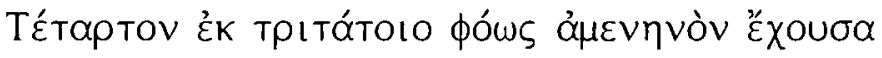

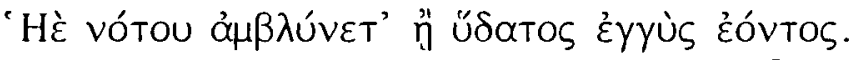

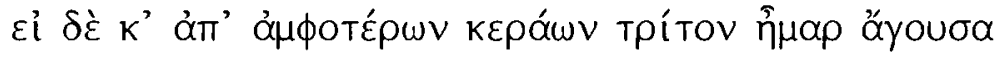

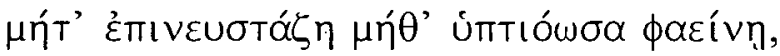



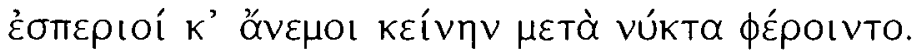

(Fenômenos, v. 783-791)

A descoberta desse acróstico (o adjetivo 8, $B Z$, que inica o verso primeiro desse trecho, é retomado pelas primeiras letras dos versos seguintes) foi feita por Jacques, em 1960, segundo Farrell (1991, p. 82); ora, Virgilio, imitando esses versos, também cria um acróstico, com sua "assinatura":

\author{
Luna reuertentis cum primum colligit ignis, \\ si nigrum obscuro comprenderit aera cornu, \\ MAximus agricolis pelagoque parabitur imber; \\ at si uirgineum suffuderit ore rubentem, \\ VEntus erit; uento semper rubet aurea Phoebe. \\ Sin ortu quarto (namque is certissimus auctor) \\ $P$ Ura neque obtusis per caelum ibit, \\ totus et ille dies et qui nascentur ab illo \\ exactum ad mensem pluuia uentisque carebunt, \\ uotaque seruati soluent in litore nautae \\ Glauco et Panopeae et Inoo Mëlicertae. (Geórgicas, I, v. 427-437)
}

Na tradução de Odorico Mendes (com alguma modernização da grafia): 
"Se, as luzes recobrando, abraça a Lua

Com atro corno a cerração, tormenta

Se apresta ao mar e à terra; mas, se as faces

Cora em pejo virgíneo, o vento é certo:

Sempre ao vento enrubece a loura Phebe.

Se pura ao quarto assomo, o que não falha, Já das pontas não romba se espacea, 0 mês, desde esse dia até que finde, Será tranqüilo e estivo; os nautas salvos Promessas pagarão na praia a Glauco, A Melicerta, Inôo e Panopéia".

Esse acróstico foi descoberto por Brown em 1963, sempre segundo Farrell. A "chave" de leitura encontra-se no adjetivo pura, tradução virgiliana para o $\alpha \alpha \theta \alpha \rho \eta ́$ de Aratos, indicando por onde se inicia a leitura; no poema latino, de baixo para cima, pulando-se um verso a cada formação da sîlaba inicial de seu nome, Publios Vergilius Maro. Evidentemente, o fato de que esse acróstico ocorra num trecho em que Virgilio imita de muito perto, reelaborando, um predecessor dá a esse "tour de force" um sabor especial: o poeta, rivalizando com Aratos, deixa a marca pessoal, a evocação de seu nome próprio!, até mesmo no aspecto mais lúdico da poesia do imitado... Note-se, por outro lado, que no trecho aparece 0 adjetivo uirgineum; tem-se discutido se na época do poeta já se associava o seu nome a uirgo, "virgem" (a vida de Donato, 35, 11 e a de Sérvio, 7-8, nos dizem que por sua vida proba, Virgílio, ou melhor, Ver-


falsa com uirgo - embora a exata significação dada ao apelativo seja objeto de polêmica); se aceitamos essa interpretação, a presença do adjetivo aqui funciona como um outro "sinalizador" para a descoberta do acróstico. ${ }^{13}$

Apontemos mais um acróstico virgiliano (mas desta vez ignoramos quem o detectou pela primeira vez), desta feita na Eneida, no episódio em que se abrem as portas do templo da Guerra:

Mos erat Hesperio in Latio, quem protinus urbes

Albanae coluere sacrum, nunc maxima rerum

Roma colit, cum prima mouent in proelia Martem,

Siue Getis inferre manu lacrimabile bellum. (VII, v. 601-604)

\footnotetext{
${ }^{13}$ Num livro recentíssimo, James 0’Hara (1996) aponta a provável relação etimológica a que o poeta aludiria aqui entre 0 nome Vergilius e uirgo. Com certa cautela, sugere que a expressão certissimus auctor "pode também sugerir, secundariamente, a noção de um 'autor' literário" (p. 264). Outra observação desse autor (p. 36) parece-nos trazer indício suplementar para a comprovação do jogo de Virgílio com seu própio nome: Aratos inicia o poema Fenômenos, imitado pelo




"Havia um costume no hespério Lácio, que sempre as cidades Albanas, sagrado, cultivaram, agora a mais poderosa de todas, Roma, cultiva, quando excitam Marte para os primeiros combates Ou (se preparam para) levar aos getas a lacrimante guerra..."

Em Lucrécio, os estudiosos apontam, entre outros, este curioso jogo de palavras do elogio a Epicuro, que sugere a etimologia de superstitio, a monstruosa superstição que teria sido vencida pelos ensinamentos corajosos dos epicuristas; antes do filósofo grego, a "religião" aterrorizava os mortais, do alto do céu, com seu aspecto horrível:

Quae caput a caeli regionibus ostendebat,

Horribili super aspectu mortalibus instans. (De Rerum Natura I, v. 65-66)

"Que das regiões do céu mostrava a cabeça,

ameaçando de cima os mortais com seu horrivel aspecto".

Aqui, Lucrécio ataca o religio, identificada à superstitio, evocada esta por sons que lhe traçam a etimologia: quod super (in) stat (West, apud, Kenney, 1974, p. 21). Dessa forma, associando "religião" a "superstição" e decompondo esta última palavra nos elementos que revelariam sua ação nefasta sobre os homens, Lucrécio insiste também de forma mais subliminar nos malefícios de um conjunto de crenças que a doutrina epicurista pretende denunciar e substituir pela explicação racional do universo.

Esse aspecto da poesia de fatura alexandrina pode parecer à primeira vista mero exibir de habilidade, arroubos de técnica para criar prazer lúdico sem maior importância para a significação, mas a análise do trecho das Geórgicas e, sobretudo, do poema VIII, mostram-nos que efeitos brilhantes grandes poetas podiam extrair desses nada inócuos jogos com as sonoridades. Assim, nenhum estudioso da poesia greco-latina deve ignorá-los nem deixar de interpretá-los como elementos importantes da significação.

Concluamos: no poema VIII de Catulo, ouve-se pelo menos mais uma voz, além das duas que estabelecem o solilóquio dramatizado com que Catullus se incita a si mesmo à renúncia - uma voz que revela a leitor o caráter auto-ilusório da renúncia de Catulo e que é criada por astúcias da forma. Se a repetição do incitamento a resistir, a tenir bon, é um dos elementos a "sinalizar" para essa leitura, o é, igualmente, porém de forma mais sutil, quase criptográfica para nossas leituras silenciosas da poesia antiga, o recurso ao anagrama: ecoando sons do nome de Lésbia com certa insistência, quando esse nome é supostamente calado, o eu-poético trai o amor não refreado, desdiz-se, contradiz-se, numa transparência irônica criada com sutileza genial.

VASCONCELLOS, P. S. Effets d'humour dans le VIII poème de Catulle. Classica, São Paulo, v. 9/10, n. 9/ 10, p. 173-186, 1996/1997. 


\section{RÉsuMÉ}

$\mathrm{D}$ ans cet article, on présente une contribution à l'étude des effets d'humour dans le poème VIII de Catulle. En fait, outre le mètre de cette pièce d'autres éléments que les savants ont signalés, un autre aspect de sa forme, encore peu aperçu, guide l'interprétation dans les sens de l'(auto) ironie: le jeu, à manière d'anagrammes imparfaites (les "hypogrammes" de Saussure), avec les sons du nom de l'aimée, apparemment silencié. C'est une des façons avec lesquelles le poète crée la différence humoristique entre ce que l'on dit et ce qui, senti et réprimé, se laisse, toutfois, transparaître.

Mots-clés: Poésie latine; Catulle; Coliambe.

\section{Referências bibliográficas}

ACHCAR, Francisco. Lírica e lugar-comum. Alguns temas de Horácio e sua presença em português.

São Paulo: Edusp, 1994.

ARISTÓTELES. Poética. Tradução de Eudoro de Souza. São Paulo: Ars Poetica, 1992.

CAIRNS, Francis. Generic composition in greek and roman poetry. Edinburgh: Edinburgh University Press, 1972.

CONTE, Gian Biagio. Virgilio, il genere e i suoi confini. Milano: Garzanti, 1984.

FARRELL, Joseph. Vergil's Georgics and the traditions of ancient epic. New York, Oxford: Oxford University Press, 1991.

FORDYCE, C.J. Catullus, a commentary. Oxford: Clarendon Press, 1961.

GUBERNATIS, Lenchantin de. Il libro di Catullo. Torino: Loescher, 1980.

KENNEY, E.J. - Viuida uis. Polemic and pathos in Lucretius I. 62-101. In: WOODMAN, T. \& WEST, D. Quality and Pleasure in Latin Poetry. Cambridge: Cambridge University Press, 1974, pp. 18-30.

MARTIN, Charles. Catullus. New Haven, London: Yale University Press, 1992.

MENDES, Odorico. Virgilio Brazileiro. Rio de Janeiro: Garnier, s./d.

0'HARA, James. J. True Names. Vergil and Alexandrian Tradition of Etymological Wordplay. Ann Arbor: The University of Michigan Press, 1966.

ORAZIO. Arte Poetica. Introduzione e commento di augusto Rostagni. Torino: Loescher, 1986.

OVIDE. Héro^ des. Paris: Les Belles Letres, 1965.

OVIDE. Les Amours. Texte établi et traduit par Henri Bornecque. Paris: Les Belles Letres, 1930.

PROPERCE. Élégies. Texte établi et traduit par D. Paganelli, Paris: Les Belles Letres, 1947.

QUEIROZ, Eça de. A Relíquia. São Paulo: Brasiliense, 1961. 
SAUSSURE. As palavras sob as palavras. Tradução de Carlos Vogt. In: Os Pensadores. 2. ed., São Paulo: Abril, 1978, p. 1.

STAROBISNKI, Jean. As palavras sob as palavras. Os anagramas de Ferdinand de Saussure. Tradução de Carlos Vogt. São Paulo: Perspectiva, 1974.

WHEELER. Catullus and the Traditions of Ancient Poetry. Berkeley: University of California Press, 1974. 